\title{
A Measurement of Clinical Profile, Complication and Outcome of the Studied Patients with Typhoid Fever
}

\author{
Rashed SKMA ${ }^{1 *}$, Akhter $\mathrm{M}^{2}$, Bari $\mathrm{MW}^{3}$, Amin $\mathrm{MR}^{4}$, Mutanabbi $\mathrm{M}^{5}$, Kawser $\mathrm{CA}^{6}$
}

\begin{abstract}
${ }^{1}$ Dr. SK. Mohammad Ali Rashed, Junior Consultant (Pediatrics), Upazila Health Complex, Charghat, Rajshahi, Bangladesh
${ }^{2}$ Dr. Murshida Akhter, Resident (General pediatrics), Sir Salimullah Medical College \& Mitford Hospital, Dhaka, Bangladesh

${ }^{3}$ Dr. Md. Washim Bari, Assistant Register, Department of Pediatrics, Rajshahi Medical College Hospital, Rajshahi, Bangladesh

${ }^{4}$ Dr. Md. Ruhul Amin, Assistant Professor, Department of Pediatrics, Rajshahi Medical College Hospital, Rajshahi, Bangladesh

${ }^{5}$ Dr. Mahbub Mutanabbi, Associate Professor, Department of Pediatrics, BSMMU, Dhaka, Bangladesh

${ }^{6}$ Choudhury Ali Kawser, Professor (ex), Department of Pediatrics, BSMMU, Dhaka, Bangladesh
\end{abstract}

DOI: $10.36347 /$ sjams.2020.v08i12.038

| Received: 05.12.2020 | Accepted: 16.12.2020 | Published: 30.12.2020

*Corresponding author: Dr. SK. Mohammad Ali Rashed

\section{Abstract}

Original Research Article

Introduction: Typhoid fever is a common pyretic illness and one of the major health complications in Bangladesh. Hence, the present study was conducted to determine the, clinical profile, complication and outcome of the studied patients suffering from typhoid fever in some of the tertiary care hospitals in Dhaka. Material \& Methods: This was a cross sectional study conducted in the Department of Paediatrics, Bangabandhu Sheikh Mujib Medical University (BSMMU), Dhaka Medical College Hospital (DMCH) and Sir Salimullah Medical College Hospital (SSMCH), Dhaka, Bangladesh for a period of one year from July 2015 to June 2016. A total number of 100 children with Typhoid fever were studied and analyze based on clinical profile, complications and outcome. During the study period febrile patients admitted in above mentioned hospital with the diagnosis of suspected typhoid fever was screened. Suspicion was made on the basis of clinical features like continued fever, toxic look, diarrhea/constipation, splenomegaly, hepatomegaly, diffuse tenderness and caeca gurgling. Clinically suspected cases undergone laboratory investigation that includes CBC, Widal test and blood culture and other tests as per individual case merits. Results: Out of 100 diagnosed typhoid fever children, 60 (60\%) were male and 40 (40\%) were female. Fever was present in all patients. Other most common appearance is loss of appetite, vomiting, diarrhea, headache and constipation. Coated tongue was the predominant examination finding followed by hepatomegaly, splenomegaly and abdominal tenderness. Sensitivity to ceftriaxone was $100 \%$ in our study while resistance to nalidixic acid was $90 \%$. Conclusion: Clinical profile of typhoid fever in children admitted in tertiary care hospitals matches to what had been seen in the past and recorded in different local and regional publications. Typhoid fever is endemic in our country and affect all ages beyond infancy as found in this study.

Keywords: Clinical Profile, Complications, Distribution, Typhoid Fever, Abdominal, Nalidixic acid.

Copyright $\left({ }_{0} 2020\right.$ The Author(s): This is an open-access article distributed under the terms of the Creative Commons Attribution 4.0 International License (CC BY-NC 4.0) which permits unrestricted use, distribution, and reproduction in any medium for non-commercial use provided the original author and source are credited.

\section{INTRODUCTION}

Until the first quarter of the 19th century, typhoid fever was not recognized as a separate clinical entity and was often confused with other prolonged febrile syndromes such as typhus fever of rickettsia origin. The word typhus is said to have been used first by Hippocrates (460 BC) to describe 'stupor' caused by fever and is thought to have been used to describe many febrile illness causing mental aberrations [1]. Typhoid means typhus-like and thus the name was given to this disease. The term enteric fever was introduced in 1869 and now includes both typhoid fever and paratyphoid fever $^{1}$. Thomas Willis is regarded as the pioneer in diagnosis of typhoid fever [2]. Again it was on the clinical picture alone [3]. Jenner in 1850 , long before $S$. typhi was discovered, put the matter beyond all reasonable doubt in an admirable and detailed comparison of the two diseases (typhus and typhoid fever) [3]. The lack of specific clinical signs complicates the diagnosis of typhoid fever, which must be distinguished from other endemic acute and sub-acute febrile illness [3]. Leukopenia and neutropenia commonly develop in typhoid fever. Mild leukocytosis can also be seen initially in children, even in uncomplicated cases, low grade normocytic anaemia, mild thrombocytopenia, modestly elevated serum transaminase and proteinuria are common [4]. In some studies from developing countries where high incidences of typhoid fever, co-agglutination test is much more reliable than culture, because so many patients have already taken antibiotics before being 
seen by a physician. Promising new enzyme immunoassay (ELISA) that detects S.typhi outer membrane proteins (OMP) is being evaluated [5]. The definitive diagnosis of typhoid fever requires isolation of the organism from the patient. Blood culture still remains the gold standard for diagnosis of typhoid fever. Culture of blood, stool, urine, rose spots, bone marrow, buffy coat of blood and streptokinase treated blood clots can all be useful in diagnosis. In untreated patients, blood cultures are usually positive in about $80 \%$ during the first week, declining to $20-30 \%$ later in the course of the disease. By the conventional blood culture method, isolation of the bacteria is positive in about $60-80 \%$ of the cases provided a large volume of blood is incubated and it takes about 3-5 days. However, recently introduced fully automatic computerized blood culture system (BACTEC) can detect positive growths within a period of 6-24 hours [6]. A sensitive and specific multiplex polymerase chain reaction (PCR) for VI antigen promises to be highly sensitive and specific, but no prospective studies on large number of typhoid cases to evaluate the specificity and sensitivity of PCR is yet available. Cost and nonavailability of equipment required may limit its application in developing countries [6].

\section{OBJECTIVES}

\section{a) General objective}

- This study was commenced to determine of Clinical profile, complication and outcome of the studied patients with typhoid fever.

\section{b) Specific Objectives}

- To measure the Clinical profile, complication of the patients with typhoid fever.

- To observe outcome of the studied patients with typhoid fever

\section{Methodology and Materials}

This was a Cross-sectional observational study. The study was carried out under the department of Pediatrics of Bangabandhu Sheikh Mujib Medical University, Dhaka Medical College Hospital and Sir Salimullah Medical College Hospital, Dhaka, Bngladesh. In the above centers, a lot of pediatric patients with typhoid fever are admitted every year for evaluation and management. Overall, period of study was July 2015 to June 2016 (One year). Ethical clearance was taken from Institutional Review Board (IRB) of BSMMU and the participants were explained that there will be no physical or social risk. The Children admitted in the Pediatrics wards of the abovementioned hospital during the study period with suspected diagnosis of typhoid fever were the study population. Children with positive blood culture were diagnosed as 'confirm case' and cases with a titer of TO $\geq 1: 160$ or rising titer of Wedel test were diagnosed as 'probable case'. All children with diagnosis of 'confirmed' or 'probable cases' admitted in those hospital during the study period were the sample. During the study period febrile patients admitted in above mentioned hospital with the diagnosis of suspected typhoid fever was screened. Suspicion was made on the basis of clinical features like continued fever, toxic look, diarrhea/constipation, splenomegaly, hepatomegaly, diffuse tenderness and caeca gurgling. Clinically suspected cases undergone laboratory investigation that includes $\mathrm{CBC}$, Widal test and blood culture and other tests as per individual case merits. To determine the sample size the following formula 100 children with the diagnosis of typhoid fever and fulfilling the inclusion and exclusion criteria's during the study period were selected purposively.

\section{Inclusion Criteria}

- Patient diagnosed as typhoid fever and admitted in mentioned hospitals during the study period.

- $\quad$ Pediatric age group of both sexes

\section{Exclusion Criteria}

- Patient with severe co-morbidities unrelated to typhoid fever.

- Patient with paratyphoid fever.

- Care-giver not willing to give written consent

\section{RESUlTS}

A total number of 100 children were selected for this study. (Figure-1) Figure 4.1 showed, out of 100 patient $60 \%$ were probable case and $40 \%$ were confirmed case of typhoid fever. (Table-1) shows the age distribution of the 100 participants. Here, chosen age group were divided into three criteria, 37 children were selected for 1-5 years group, 35 children for the 510 years group and 28 were selected for above 10 years aged group. (Figure-2) showed most (87\%) of the children had improved sanitation facility in their home (Table-2). Personal hygiene practice by the studied children, the percent of children were quite good particularly in respect to washing hand after defecation as shown in this table. However, a good number of children are exposed to street food (Figure-3). Fever was universal, followed by anorexia $(60 \%)$ and nausea/ vomiting (35\%). Abdominal complaints were also common \{diarrhea $(30 \%)$, abdominal pain $(25 \%)$ constipation (15\%)\}. (Table-3) showed electrolyte imbalance and shock in $2 \%$ patient while hepatitis, shock and pancytopenia present in $1 \%$ cases. (Table-4) showed most $(86 \%)$ of the children had abatement of fever $<5$ days while $58.1 \%$ children achieved normal liver span between 3-5 days of treatment and mortality was $0 \%$. 


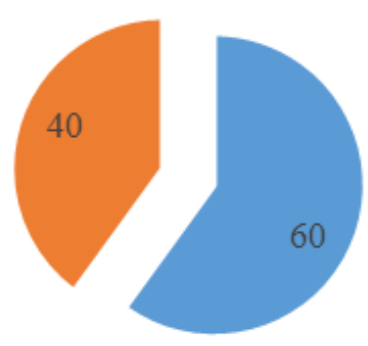

- Probable case of typhoid - Conformed case of typhoid

Fig-1: Distribution of typhoid patient according to case definition $(n=100)$

Table-1: Age distribution of the studied participants $(n=100)$

\begin{tabular}{|l|l|l|}
\hline Age & $\mathbf{N}$ & \% \\
\hline 1-5 years & 37 & 37 \\
\hline 5-10 years & 35 & 35 \\
\hline$>10$ years & 28 & 28 \\
\hline
\end{tabular}

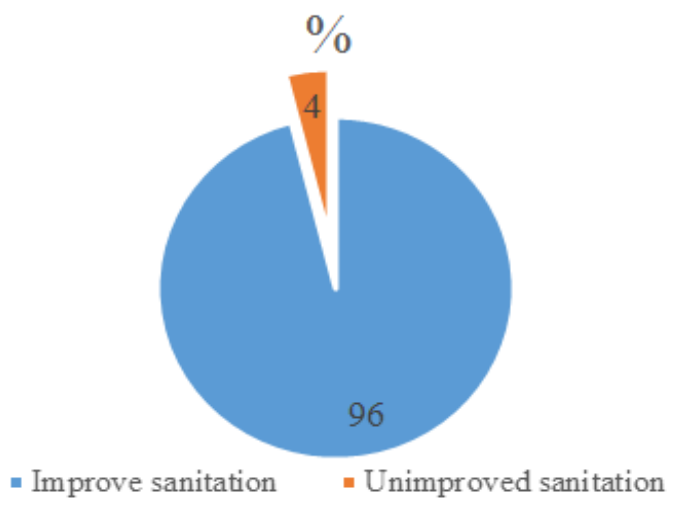

Fig-2: Distribution of children on availability of sanitary facility $(\mathbf{n}=100)$

Table-2: Distribution of children as personal hygiene practice and exposure to outside food (n=100)

\begin{tabular}{|l|l|l|}
\hline Subject & Number of patients & $\%$ \\
\hline Hygiene category & 60 & 60 \\
\hline Hand wash before meal with soap & 90 & 90 \\
\hline Hand wash after defecation with soap & \multicolumn{2}{|l|}{} \\
\hline Food habit & 64 & 64 \\
\hline Accustomed to street food & 42 & \\
\hline Male & 22 & \\
\hline Female & & \\
\hline
\end{tabular}

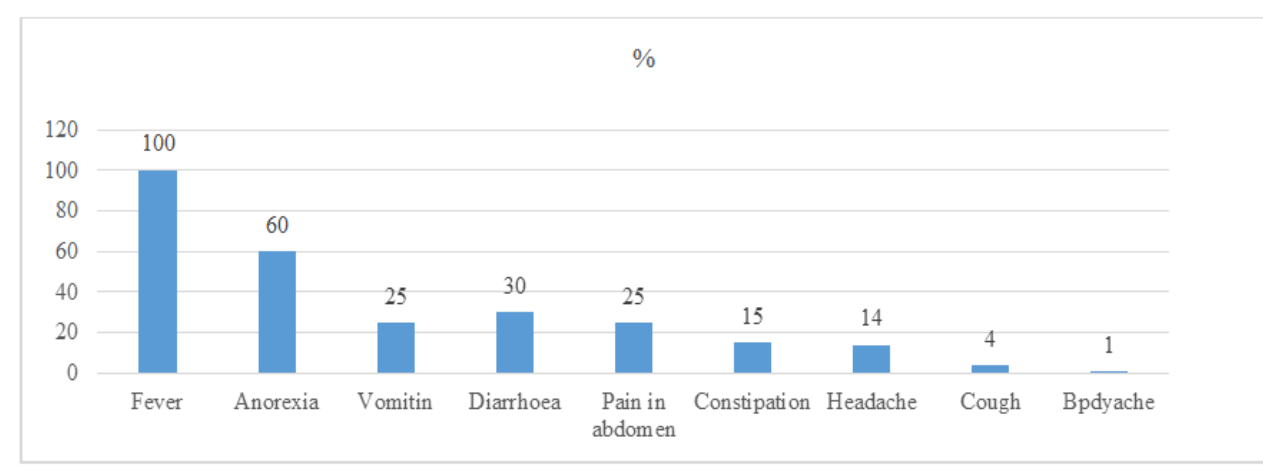

Fig-3: Presenting symptoms of patients $(n=100)$ 
Table-3: Complication of children with typhoid fever $(n=100)$

\begin{tabular}{|l|l|l|}
\hline Complications & Number of children & \% \\
\hline Hepatitis & 1 & 1 \\
\hline Thrombocytopenia & 2 & 2 \\
\hline Pancytopenia & 1 & 1 \\
\hline Electrolyte imbalance & 2 & 2 \\
\hline Shock & 1 & 1 \\
\hline
\end{tabular}

Table-4: Outcome of the children with typhoid fever $(n=100)$

\begin{tabular}{|l|l|l|}
\hline Parameters & Number of children & \% \\
\hline Defervesence from day of treatment & & \\
\hline$<5$ days & 83 & 83 \\
\hline 5-7days & 16 & 16 \\
\hline$>$ 7days & 1 & 1 \\
\hline Normal liver span from day of treatment & & \\
\hline$<3$ days & 25 & 40.3 \\
\hline 3-5 days & 36 & 58.1 \\
\hline$>$ days & 1 & 1.6 \\
\hline Mortality & 0 & 0 \\
\hline
\end{tabular}

\section{DISCUSSION}

The present study showed male preponderance 1.5:1. This is consistent with the result of [7, 8]. However, other report suggests similar prevalence amongst both sexes [9]. Probable explanation might be that in a male dominant society like ours male child has higher access to medical care. It may also be due to the fact that the male children are more independent and has more chance of exposure to street food. Most (87\%) of the children had improved sanitation facility in their home but needs to be cent percent. According to BBS 2014 report the distribution of sanitation in Dhaka division were improved sanitation $70 \%$, unimproved sanitation $29 \%$, others $1 \%$. Though the use of improved sanitation in case of typhoid patient were similar to general population in Dhaka but percentage of hand washing seems to be less. Majority of children in present study used 'safe' water, like boiling or using filtered water, but there is no study that document effect of boiling or filtering from our country. According to report of BBS 2014 source of drinking water in Dhaka division-supply water-39.7\%, tube well water-59.4\%, others- $0.7 \%$. So it seems that consumption of unboiled water $(45 \%)$ was relatively high in children suffering from typhoid fever. Similarly, the personal practice as found in the present study cannot explain such high rate. A high percent of children is exposed to street food as was observed by [10] in their observation $(79.17 \%$ of studied children). The clinical presentation of present study matches to different local and regional publications by [11-13]. However, classical typhoid fever presenting as "stepladder fashion" was not seen in present study. Atypical presentations are rare and may be manifested as cough, jaundice, burning micturition, joint pain and others as shown in table. Islam and colleagues [14] in a similar study from Bangladesh on clinical presentation of typhoid fever in children presented with similar atypical pattern. In our study abdominal tenderness was present in $(25 \%)$ patient. In another study done by [15] showed, abdominal tenderness in only $8 \%$ of patient. Jaundice was present in only $(01 \%)$ patient in our study, whereas [16] reported $04 \%$ in their series. Contrary to adult, relative bradycardia is not common in children, which was observed in only 3 patient in present study, which is similar to the observation of [17]. Rose spot was observed in none of our series, which is in conformity with the findings of Yaramis A et.al [18]. The probable explanation of absence of rose spot is that, it is difficult to find in dark skinned children. According to a study mild jaundice may occur in typhoid fever and may be due to hepatitis, cholangitis and cholecystitis. Biochemical changes indicative of hepatitis are common during the acute stage [6]. This study showed two of the major complications are thrombocytopenia and Electrolyte imbalance in typhoid fever. In the present study, $90 \%$ patients were resistant to nalidixic acid. Khanam F et al., [19] in their study found $100 \%$ isolates from were resistant to nalidixic acid. In existing study there were few complications and mortality rate was nil which was similar to the findings of [20].

\section{Limitations OF THE STUdY}

This was a cross-sectional observational study with small sample size, which doesn't reflect the scenario of the whole country.

\section{Conclusion and Recommendations}

Clinical profile of typhoid fever in children admitted in tertiary care hospitals matches to what had been seen in the past and recorded in different local and regional publications. Typhoid fever is endemic in our country and affect all ages beyond infancy as found in this study. However, Nalidixic acid associated resistance was found to be high and the reason behind that can be the poor sanitary condition and nonavailability of safe water. Recommendations: Efforts 
should be taken to find the complications of typhoid fever and solve them. Continuous surveillance of typhoid fever will be done to see the changes in demographic charecteristics.

Funding: No funding sources.

Conflict of Interest: None declared.

Ethical Approval: The study was approved by the Institutional Ethics Committee.

\section{REFERENCES}

1. Singh B. Symposium: Typhoid Fever. Journal Indian Academy of Clinical Medicine. 2001; 2:110

2. David AP, Michael E, Samuell M. Salmonella species including Salmonella typhi: In : Mandell GL, Bennett JE, Dolin R, editors, Principles and practice of infectious disease, Churciil Livingstone, $6^{\text {th }}$ edition. 2004; 1:2636-54.

3. Parry CM, Hoa NT, Diep TS, Wain J, Chinh NT, Vinh H, Hien TT, White NJ, Farrar JJ. Value of a single-tube Widal test in diagnosis of typhoid fever in Vietnam. Journal of clinical microbiology. 1999 Sep 1; 37(9):2882-6.

4. Haq SA, Alam MN, Hossain SM, Dhar UK, Rahim S, Rahman M, Ahmed T, Tahir M. A study of prolonged pyrexia in Dhaka. Bangladesh Medical Research Council bulletin. 1996 Apr; 22(1):33-42.

5. Shukun W, Qian W, Conjia C, Deshen S, Xianhua W. Value of a single serum widal agglutination test in diagnosis of paratyphoid fever A. International Research journal. 2011; 1:209-14.

6. Bhutta ZA. Salmonellosis; Enteric Fever (Typhoid fever), In: Kliegman RM, Behrman RE, Jenson HB, Stanton BF. editors. Nelson's text book of pediatrics. 19th ed. New Delhi: Elsevier Saunders. 2008; 1186-91.

7. Kumar S, Rizvit M, Berry N. Rising prevalence of enteric fever due to multidrug resistant salmonella: an epidemiological study. $J$ of medical microbiology. 2008; 57:1247- 50.

8. Abdullah FE, Haider F, Fatima K, Irfan S, Iqbal MS. Enteric Fever in Karachi: Current Antibiotic Susceptibility of Salmonellae Isolates. Journal of the College of Physicians and Surgeons Pakistan. 2012; 22:147-150
9. Shah G, Ghimire A, Shrestha S. Clinical profile of culture proven enteric fever in children at university teaching hospital, Nepal. Journal of Patan Academy of Health Sciences. 2014;1(2):425.

10. Khan MR, Rahman E 2011. Essence of Paediatrics. $4^{\text {th }}$ edition, pp.395-397.

11. Haq SA, Alam MN, Hossain SM, Ahmed T, Tahir M. Value of clinical features in the diagnosis of enteric fever. Bangladesh Medical Research Council Bulletin. 1997 Aug; 23(2):42-6.

12. Ganesh R, Janakiraman L, Vasanthi T, Sathiyasekeran M. Profile of typhoid fever in children from a tertiary care hospital in ChennaiSouth India. The Indian Journal of Pediatrics. 2010 Oct 1; 77(10):1089-92.

13. Topley JM. Mild typhoid fever. Arch Dis child. 1986; 61:164-7.

14. Shah G, Ghimire A, Shrestha S. Clinical profile of culture proven enteric fever in children at university teaching hospital, Nepal. Journal of Patan Academy of Health Sciences. 2014; 1(2):425.

15. Islam MS, Rahman MH. Karim B, Khan RH. 'Clinical Presentation of Typhoid Fever', Ibrahim Card Med J. 2011; 1:40-44.

16. Lakhotia M, Gehlot RS, Jain P, Sharma S, Bhargava A. Neurological manifestations of enteric fever. J Indian Acad Clin Med. 2003 Jul;4(3):196-9.

17. Hammad OM, Hifnawy T, Omran D, El Tantawi MA, Girgis NI. Ceftriaxone versus chloramphenicol for treatment of acute typhoid fever. Life Sci J. 2011; 8(2):100-5.

18. Yaramis A, Yildirim I, Katar S, Ozbek MN, Yalçin I, Tas MA, Hosoglu S. Clinical and laboratory presentation of typhoid fever. International Pediatrics. 2001; 16(4):227-31.

19. Khanam F, Sayeed MA, Choudhury FK, Sheikh A, Ahmed D, Goswami D, Hossain ML, Brooks A, Calderwood SB, Charles RC, Cravioto A. Typhoid fever in young children in Bangladesh: clinical findings, antibiotic susceptibility pattern and immune responses. PLoS Negl Trop Dis. 2015 Apr 7; 9(4):e0003619.

20. Chowta MN, Chowta NK. Study of clinical profile and antibiotic response in typhoid fever. Indian Journal of Medical Microbiology. 2005 Apr 1; 23(2):125-27. 